\title{
LATTICE DISCRETE PARTICLE MODELING OF SHEAR FAILURE IN SCALED GFRP REINFORCED CONCRETE BEAMS WITHOUT STIRRUPS
}

\author{
*University of South Carolina \\ Columbia, SC USA \\ e-mail: khodaie@email.sc.edu \\ ${ }^{\dagger}$ University of South Carolina \\ Columbia, SC USA \\ e-mail: fmatta@sc.edu \\ ${ }^{\dagger}$ Rensselaer Polytechnic Institute \\ Troy, NY USA \\ e-mail: alnagm2@rpi.edu
}

SINA KHODAIE ${ }^{*}$, FABIO MATTA ${ }^{\dagger}$ AND MOHAMMED ALNAGGAR ${ }^{\dagger \dagger}$

Key words: LDPM, Parameter calibration, Shear failure, Model validation

\begin{abstract}
This paper discusses the calibration of a concrete lattice discrete particle model (LDPM), and its preliminary validation for the case of shear failure in scaled glass fiber reinforced polymer (GFRP) reinforced concrete (RC) beams without stirrups. First, the model parameters were defined based on: (a) the design of the concrete mixture that was used to fabricate scaled beam specimens; and (b) a literature database of meso-scale concrete parameters. Second, the calibration was refined to reach satisfactory agreement between numerical and experimental compression stress-strain curves as obtained by testing concrete cylinders in accordance with ASTM C469. The calibrated model was then used for the numerical simulation of four-point bending load tests on two slender GFRP RC beams without stirrups, and having an effective depth of 146 and $292 \mathrm{~mm}$, respectively. The beam computational models are discussed vis-à-vis experimental data based with respect to elastic response, post-cracking stiffness degradation and damage progression, ultimate strength, and failure mode. The proposed model accurately approximates the pre- and post-cracking flexural stiffness, and holds promise to predict the shear strength of scaled GFRP RC slender beams without stirrups, provided that a suitable rebar-concrete bond stress-slip law is implemented.
\end{abstract}

\section{INTRODUCTION}

It is widely accepted that different shear mechanisms contribute to the shear strength of reinforced concrete ( $\mathrm{RC})$ beams [1]. In $\mathrm{RC}$ beams without stirrups and reinforced with either steel or corrosion-resistant glass fiber reinforced polymer (GFRP) bars, shear forces are resisted by the uncracked concrete above the neutral axis, through aggregate interlocking and tensile cohesive stresses along diagonal cracks, and dowel action exerted by the flexural reinforcement. When using a similar amount of GFRP bars instead of steel bars as flexural reinforcement, a reduced shear strength is attained due to the markedly lower (i.e., resin-dominated) axial stiffness and shear strength of the bars [2]. To this end, ACI 440.1R-15 [3], provides guidance to estimate the nominal shear strength of GFRP RC beams under the assumption that shear forces are resisted primarily through the uncracked concrete 
above the neutral axis. The decrease in the shear strength of GFRP RC beams without shear reinforcement at increasing effective depths has been documented in the literature, and is exacerbated because of the lower stiffness of GFRP with respect to steel bars $[2,4,5]$.

Bentz et. al. [5] presented an analytical approach based on the Modified Compression Field Theory (MCFT) [6], which allows to effectively estimate the shear strength of steel and FRP RC beams with different depths [7]. Here, aggregate interlock is assumed as the primary shear-resisting mechanism, and the maximum shear stress is a function of concrete compressive strength, maximum aggregate size, and crack width. In particular, size effect is attributed to the formation of wider cracks, with reduced contributions of aggregate interlocking to shear strength [8].

Bažant et al. [9] explained this size effect based on the ratio of the fracture process zone (FPZ) length to the depth of the uncracked concrete ligament above the critical shear crack, along which shear-compression and cohesive stresses are transferred. As the beam depth decreases, the size of the FPZ approaches that of the ligament, resulting in a nearly uniform compression stress distribution at failure. For larger sizes, because of the fixed length of the FPZ, such ratio decreases, resulting in a progressively less uniform compressive stress profile and reduced sectional shear stress at failure [10].

To date, the physical explanation of size effect remains controversial. In addition, no mainstream numerical tools are available to practitioners and researchers for predicting shear strength in scaled RC beams, and advancing the understanding of the associated shear-resisting mechanisms. Continuum based models (e.g., smeared-crack [11], plasticdamage [12]) have been implemented in commercial finite element (FE) codes to simulate concrete fracture. However, a notable limitation is that results are mesh-sensitive. The extended FE method (XFEM) [13] was introduced to overcome mesh sensitivity and stress singularities at crack tips. Other continuum based methods such as cohesive crack [11] and crack band models [14] have been also introduced to simulate the FPZ in concrete. Meso-scale models enable one to directly simulate the concrete meso-structure and FPZ, which is necessary for the realistic simulation of fracture phenomena in concrete. These models use FEs [15], discrete elements (DEs) [16] or lattice systems [17-19] as the interface between aggregate particles.

The Lattice Discrete Particle Model (LDPM) [20,21] is a meso-scale model for concrete that has the ability to realistically simulate the concrete inelastic behavior, including fracture. The LDPM tensionsoftening constitutive law is based on the cohesive crack model, which allows LDPM to capture energetic size effects. Also, the discrete formulation with long-range interaction combined with a shear-frictional constitutive law allows to simulate aggregate interlocking. The LDPM is currently implemented in the Modeling and Analysis of the Response of Structures (MARS) software [22]. Since its nodes include both displacement and rotational degrees of freedom, the LDPM in MARS can be conveniently implemented in conjunction with continuum FEs. MARS has a library of different $\mathrm{FE}$ formulations such as 3D, shell and beam elements that are suitable to model concrete reinforcement as well as loading plates and supports. Constraints and different types of contact algorithms are also available to model contact interfaces between concrete and reinforcement, loading plates and supports, enabling the simulation of shear force transfer through dowel action.

The potential of LDPM to accurately and realistically simulate shear-resisting mechanisms in deep and slender steel-RC beams has been recently demonstrated [2325]. In this paper, the LDPM parameters are calibrated and validated through experimental and literature-based data. Then, the model is used to simulate the response of four scaled GFRP RC beams that are loaded using fourpoint bending setups. The simulation results are discussed based on supporting evidence from load tests that were performed on actual physical specimens [4]. 


\section{COMPUTATIONAL MODELS FOR GFRP RC BEAMS}

This section presents the computational models for concrete and GFRP bars that are used herein.

\subsection{Lattice Discrete Particle Model}

The Lattice Discrete Particle Model (LDPM) is a meso-scale model for concrete that considers aggregate particles and mortar as its geometric representation. It simulates the mechanical interaction of the adjacent particles by means of polyhedral cells that interact through triangular facets (Fig. 1), and a lattice system connecting the particle centers.

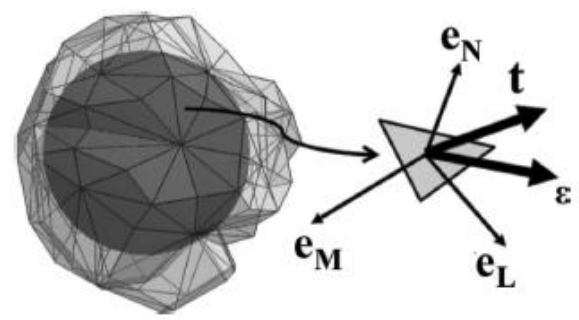

Figure 1: LDPM cell around aggregate particle [23]

LDPM uses rigid body kinematics to describe the deformation of the lattice-particle system and the displacement jump, $\llbracket \mathbf{u}_{C} \rrbracket$, at the centroid of each facet. Strain measures are $e_{N}$ $=\mathbf{n}^{\mathrm{T}} \llbracket \mathbf{u}_{C} \rrbracket / \ell, e_{L}=\mathbf{I}^{\mathrm{T}} \llbracket \mathbf{u}_{C} \rrbracket / \ell$, and $e_{M}=\mathbf{m}^{\mathrm{T}} \llbracket \mathbf{u}_{C} \rrbracket / \ell$, where $\ell=$ inter-particle distance, and $\mathbf{n}, \mathbf{l}$, and $\mathbf{m}$ are the unit vectors that define the local reference system of each facet (Fig. 1).

The behavior of the material is governed by a vectorial constitutive law at the centroid of each facet. Under elastic deformations, normal and shear stresses are assumed to be proportional to the associated strains, i.e., $t_{N}=$ $E_{N} e_{N}, t_{M}=E_{T} e_{M}$, and $t_{L}=E_{T} e_{L}$, where $E_{N}=$ $E_{0}, E_{T}=\alpha E_{0}\left(E_{0}=\right.$ normal modulus, $\alpha=$ shearnormal coupling parameter). For the inelastic behavior of concrete, LDPM represents three mechanisms: (1) fracture and cohesion for tensile and tensile-shear stresses; (2) compaction and pore collapse for confining compressive stresses; and (3) friction for compressive-shear stresses. The constitutive laws of LDPM inelastic behavior are reported elsewhere [20]. Finally, the dynamic equilibrium equation of each particle completes the set of governing equations for the LDPM.

\subsection{GFRP material model}

GFRP is a composite material that exhibits a linear elastic behavior in tension until failure. It has a relatively higher tensile strength than conventional steel bars but its elastic and shear modulus are significantly lower $\left(E_{G F R P} \approx\right.$ $\left.0.2 E_{\text {steel }}, G_{G F R P} \approx 0.1 G_{\text {steel }}\right)$. For a GFRP bar subject to axial and shear stresses $(\sigma, \tau)$, the selected failure criterion is given as $\left(\sigma / \sigma_{u}\right)^{2}+$ $\left(\tau / \tau_{u}\right)^{2}=1$, where $\sigma_{u}$ is the uniaxial tensile strength, and $\tau_{u}$ is the shear strength [26]. While this failure criterion is not implemented in MARS [22], it is herein applied in the postprocessing phase using bar axial and shear force history output data.

The bar elements in MARS follow Reissner's theory [27], which contemplates a stiffness multiplier for the transverse direction. This allows the shear stiffness factor $G_{G F R P} / G_{\text {steel }} \approx 0.1$ to be accounted for, thereby more faithfully simulating shear stresses and deformations in the GFRP reinforcement.

\section{CALIBRATION OF LDPM PARAMETERS}

LDPM is characterized by two sets of parameters. The first set defines the geometry of the concrete meso-structure, and is defined primarily from information on the mix design. The second set defines the constitutive laws, which approximate the elastic and inelastic response at the potential failure surfaces in the meso-structure, which are referred to as "facets". The inelastic response of facets includes fracture in tension and shear, pore collapse and compaction, and friction. When concrete specimens subject to uniaxial compression are not also subject to confining pressures, the meso-scale parameters associated with compaction and pore collapse behavior have a negligible effect on the stressstrain response [21]. For this reason, these parameters are neglected herein. Ideally, a rigorous calibration of LDPM material parameters for fracture and shear response 
requires the numerical fitting of loaddisplacement curves from unconfined compression tests (ASTM C469) and fracture tests such as splitting tensile strength (ASTM C496), modulus of rupture (ASTM C78), three-point bending, and direct tension tests. However, in most cases, these tests are not performed in the same experimental campaign, and only compressive strength results are typically provided. Therefore, in this paper, it is demonstrated how to use data from literature and standard codes to define reasonable values for the parameters needed. It is noted that reduced data sets for calibration may result in over-determinate problems, which can yield multiple possible combinations of parameter values for a given limited data set. To this end, the availability of different experimental data from concrete characterization tests (e.g., ASTM C39 or, less frequently, ASTM C469) may be sufficient to select accurate parameters.

In this section, the available data for parameter identification are provided. Then, the candidate model and related calibration procedure are presented.

\subsection{Uniaxial compression stress-strain data}

In this paper, the available data for the calibration of LDPM parameters consist of: (1) information on the concrete mix design; and (2) stress-strain curves from uniaxial compression tests on 30 unconfined 101-by$203 \mathrm{~mm}$ cylinders, which were performed in conformance with ASTM C469. Here, the compressive load is applied in force-control mode until the load steadily decreases and the specimen exhibits a distinct fracture pattern. Low-friction pads are inserted between the cylinder surfaces and the loading platens to minimize lateral confinement. The dominant fracture pattern is columnar vertical cracking through both ends of the specimen, without well-formed cones. In Fig. 2, the envelope of stress-strain diagrams is presented, together with representative curves and peak compressive stress markers. The average cylinder compressive strength is $40.3 \mathrm{MPa}$, with a standard deviation of $2.3 \mathrm{MPa}$.

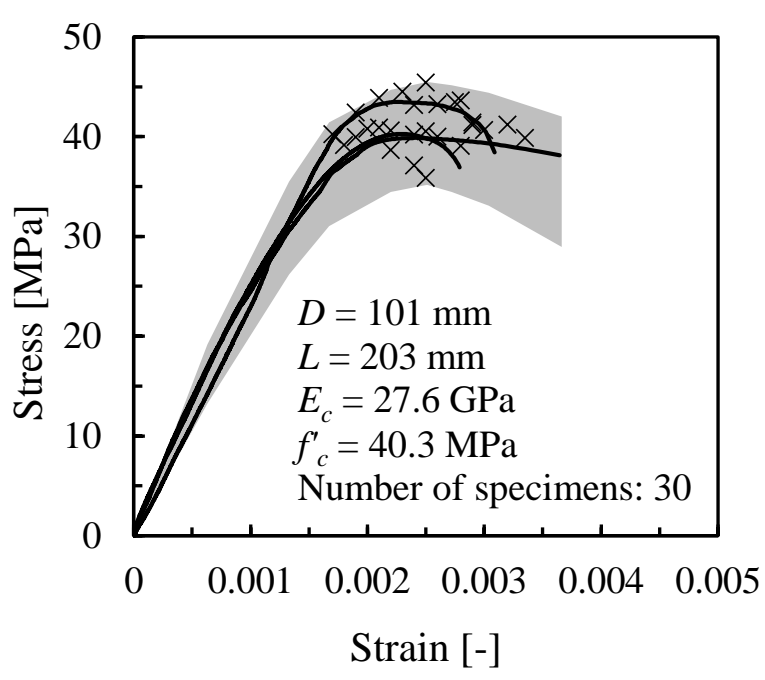

Figure 2: Uniaxial compression stress-strain response of concrete cylinders

\subsection{Calibrated model}

The geometric and material parameters of LDPM are summarized in Table 1 and Table 2 , respectively, and are discussed in the following sub-sections.

Table 1: LDPM geometric parameters

\begin{tabular}{l|c|c}
\hline Cement mass content $\left[\mathrm{kg} / \mathrm{m}^{3}\right]$ & $c$ & 508.5 \\
\hline Water-to-cement ratio & $w / c$ & 0.4 \\
\hline Aggregate-to-cement ratio & $a / c$ & 5.2 \\
\hline Maximum aggregate size $[\mathrm{mm}]$ & $d_{a}$ & 12.7 \\
\hline Fuller coefficient & $n_{F}$ & 0.48 \\
\hline Minimum aggregate size $[\mathrm{mm}]$ & $d_{0}$ & 6 \\
\hline
\end{tabular}

Table 2: LDPM material parameters

\begin{tabular}{l|c|c}
\hline Normal modulus [GPa] & $E_{0}$ & 40 \\
\hline Shear-normal coupling parameter & $\alpha$ & 0.24 \\
\hline Shear strength ratio & $\sigma_{s} / \sigma_{t}$ & 4.2 \\
\hline Tensile strength [MPa] & $\sigma_{t}$ & 3.6 \\
\hline Tensile characteristic length [mm] & $l_{t}$ & 180 \\
\hline Softening exponent & $n_{t}$ & 0.2 \\
\hline Initial friction & $\mu_{0}$ & 0.2 \\
\hline Asymptotic friction & $\mu_{\infty}$ & 0 \\
\hline Transitional stress [MPa] & $\sigma_{N 0}$ & 600 \\
\hline Compressive strength [MPa] & $\sigma_{c 0}$ & 100 \\
\hline Densification ratio & $E_{d}$ & 1 \\
\hline Initial hardening modulus ratio & $H_{c 0} / E_{0}$ & 0.4 \\
\hline Volumetric deviatoric coupling & $\beta$ & 0 \\
\hline Transitional strain ratio & $\kappa_{c 0}$ & 2 \\
\hline Deviatoric strain threshold ratio & $\kappa_{c 1}$ & 1 \\
\hline Deviatoric damage parameter & $\kappa_{c 2}$ & 5 \\
\hline
\end{tabular}


The representative uniaxial compression stress-strain curve of the simulated concrete using these parameters is illustrated in Fig. 3.

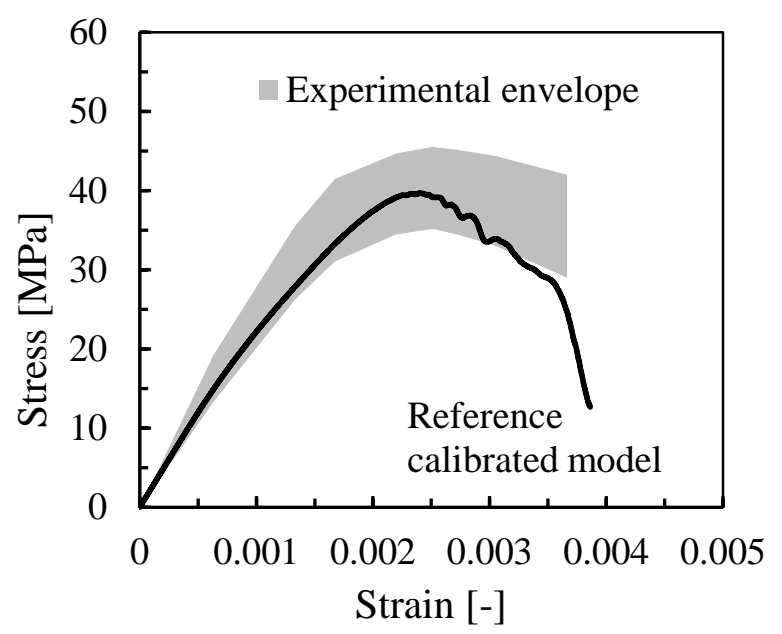

Figure 3: Uniaxial compression stress-strain curve for calibrated concrete LDPM

The compressive strength of this calibrated model is $39.7 \mathrm{MPa}$. The parameters that are not discussed herein are explained in reference [20], and are selected to be similar to concrete models with compressive strengths of about 40 $\mathrm{MPa}$ (from [21]).

\subsection{Geometric parameters}

The geometric parameters of LDPM define the size distribution, number, and position of the aggregate particles within the concrete volume. The aggregate particles are randomly placed from the largest particle to a predefined cut-off (smallest) particle size using a randomly distributed positioning try-reject algorithm [20]. The statistical representation of the concrete meso-structure is achieved by generating a particle population based on the aggregate size distribution. Thus, random positioning of aggregates in each simulation could change the position of the fracture onset, and affect the crack paths in the concrete. The generation algorithm creates samples that have average response and variances that lie within the experimental data [21].

Related parameters, which can be obtained directly from the concrete mix design, include (Table 1): (1) cement mass content, $c$; (2) water-to-cement ratio, $w / c$; (3) aggregate-tocement ratio, $a / c$; (4) Fuller coefficient, $n_{F}$; and (5) maximum aggregate size, $d_{a}$. In addition, the minimum aggregate size, $d_{0}$, specifies the resolution of the model and needs to be defined by the user. Selecting a smaller value for $d_{0}$ increases the number and the direction of the possible crack paths in the meso-structure, making it possible to generate finer crack paths, but it does so by dramatically increasing computational costs. Modifying the minimum aggregate size changes the scale of the simulation and, consequently, the constitutive laws. Therefore, LDPM parameters should be recalibrated for the comprehension of a finer scale. It is recommended that the selection of the minimum aggregate size be such that at least $30 \%$ of the aggregate mass is simulated [21].

In this paper, the selection of the concrete parameters is based on the mix design used for actual GFRP RC beams without stirrups [4], which were designed to fail in shear and load tested under four-point bending. The six parameters are reported in Table 1.

\subsection{Material parameters}

The procedure for calibrating the material parameters consists of: (1) determining the related macroscopic parameters and the effect of each meso-scale parameter on the stressstrain curve; (2) assigning a reasonable range for each meso-scale parameter based on values available from the literature; and (3) selecting candidate values based on a parametric analysis of the effect of each meso-scale parameter on the compression stress-strain response of concrete cylinders.

\subsubsection{Elastic behavior}

The two meso-scale parameters that describe the elastic response of LDPM are normal modulus, $E_{0}$, and shear-normal coupling parameter, $\alpha . E_{0}$ controls the normal stiffness, and $\alpha$ is the multiplier for the shear stiffness of the facets. These parameters are linked to macroscopic parameters of concrete, i.e., Young's modulus, $E_{c}$, and Poisson's ratio, $v$ [20]. The elastic part of the stress-strain curve in Fig. 2 provides information for determining $E_{0}$. Based on the range for the 
elastic modulus in Fig. 2, 34-48 GPa is taken as a representative range for $E_{0}$, and a value of $40 \mathrm{GPa}$ is selected for the candidate model. The typical value for the Poisson's ratio in normal-weight concrete is 0.18 [28], which correlates well with the selected value of 0.24 for $\alpha$.

\subsubsection{Fracture behavior in pure tension}

The two meso-scale parameters that govern the fracture and softening behavior of the facets are tensile strength, $\sigma_{t}$, and tensile characteristic length, $l_{t} . \sigma_{t}$ describes the maximum tensile stress in the facets in pure tension. It is comparable to the value of the macroscopic strength acquired from splitting tensile tests, $f_{t}^{\prime}$ [29]. The ACI 318 code [30] suggests a range of $3.2 \mathrm{MPa}$ to $4 \mathrm{MPa}$ for $f_{t}^{\prime}$, for the compressive strength range in Fig. 2. Also, $\sigma_{t}$ directly affects the compressive strength of concrete as splitting mechanisms contribute to failure, due to the meso-scale strut-and-tie mechanisms of load distribution within the concrete meso-structure.

The parametric study of the effect of $\sigma_{t}$ on the uniaxial compression stress-strain response vis-à-vis the experimental envelope in Fig. 2 is presented in Fig. 4. The black curve represents the reference model. Increasing $\sigma_{t}$ results in higher compressive strength (as expected) and delays post-peak softening. Numerical simulations of concrete cylinder splitting suggest that $\sigma_{t}=3.6 \mathrm{MPa}$ yields a suitable correlation between $f_{t}^{\prime}$ and $\sigma_{t}$.

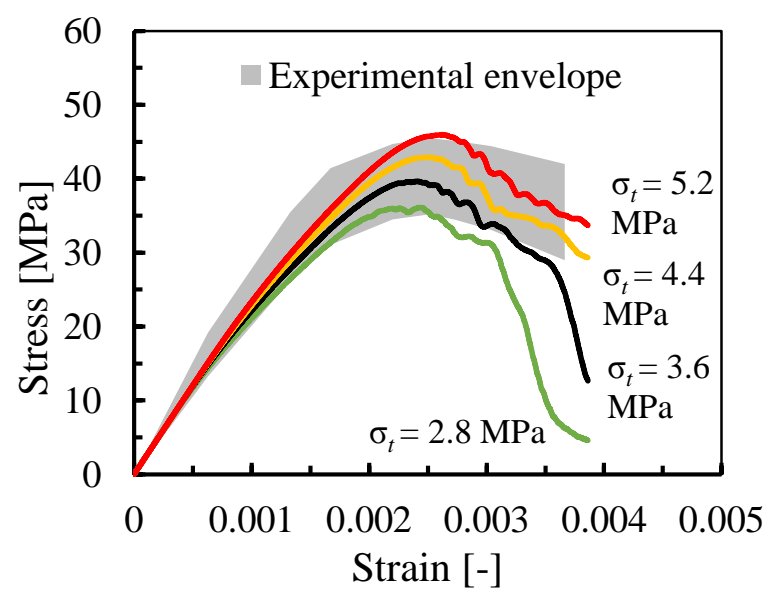

Figure 4: Compression stress-strain response of LDPM model as function of facet tensile strength, $\sigma_{t}$
The tensile characteristic length, $l_{t}$, governs the tensile softening modulus of the facets. This parameter is related to the meso-scale fracture energy, $G_{t}$ [20]. $G_{t}$ is found to be equivalent to the initial fracture energy, $G_{f}$, which is size independent [29] as it is the fracture energy related to the onset of the cracking, and can be considered as a material property. Instead, the total fracture energy, $G_{F}$, is the fracture energy required for the cracking to propagate through the specimen, and thus it is size dependent and tends to increase as the size of the specimen increases [29]. However, based on statistical analysis on a large experimental dataset, $G_{F} \approx 2.5 G_{f}$ [31]. Typically, the literature [32-34] reports $G_{F}$ from three point bending (TPB) tests, and suggests $60-150 \mathrm{~N} / \mathrm{m}$ as a reasonable range. The results of numerical TPB tests conducted on notched beams in accordance to RILEM [35] suggest that using the range 100-400 $\mathrm{mm}$ for $l_{t}$ results in the numerical $G_{F}$ to lie within the suggested range. The parametric study in Fig. 5 illustrates the effect of $l_{t}$ on the compressive strength and post-peak softening behavior. As a result, a value of $180 \mathrm{~mm}$ is selected for $l_{t}$.

\subsubsection{Fracture behavior in shear-tension}

The meso-scale parameters that govern the interaction between shear and tensile behavior of the facets are the shear strength ratio, $\sigma_{s} / \sigma_{t}$, and the softening exponent, $n_{t}$.

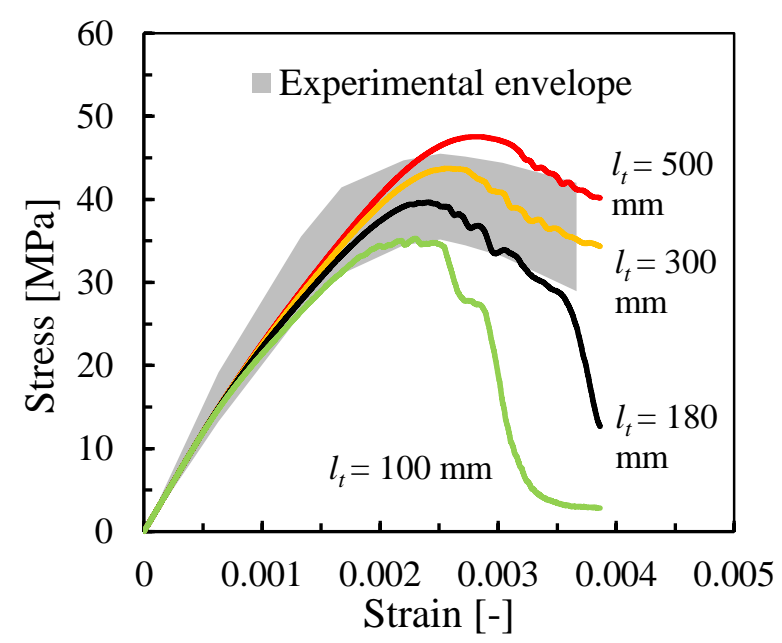

Figure 5: Compression stress-strain response of LDPM model as function of tensile characteristic length, $l_{t}$ 
The parameter $n_{t}$ modifies the softening of facets in tension in presence of shear stresses. The macroscopic effect of this parameter is the change in post-peak slope of the compression stress-strain curve. This parameter also has a minor effect on the concrete compressive strength and, based on the available literature [21], its value is set to 0.2 . The parameter $\sigma_{s} / \sigma_{t}$ defines the ratio of the shear to tensile strength of the facets. It greatly influences the strength limit of the facets when tensile and shear stresses are present as the strength limit of the facets is proportional to $\left(\sigma_{s} / \sigma_{t}\right)$ [20]. Therefore, this parameter has a major influence on the concrete compressive strength. As illustrated in Fig. 6, variations in the value of $\sigma_{s} / \sigma_{t}$ significantly affect compressive strength, with negligible consequences on the pre- and postpeak slope of the stress-strain curve.

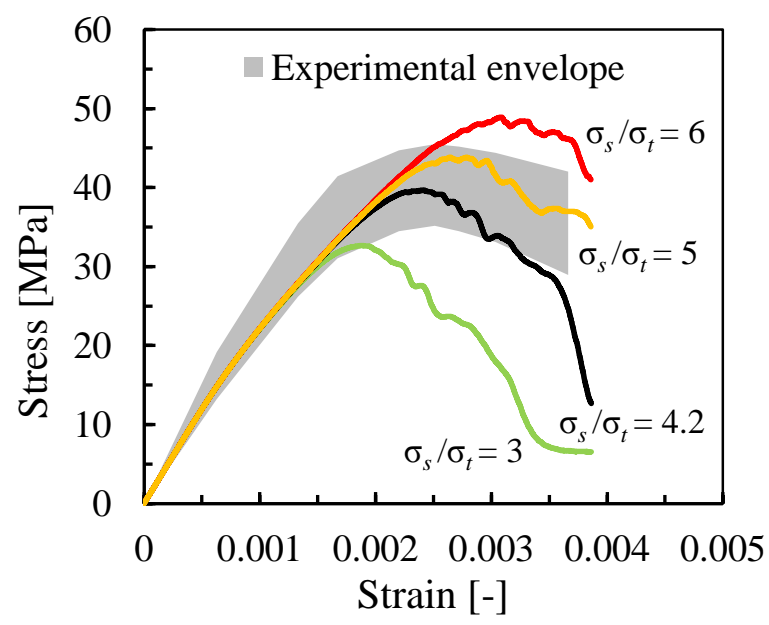

Figure 6: Compression stress-strain response of LDPM model as function of shear strength ratio, $\sigma_{s} / \sigma_{t}$

Here, a reasonable strategy to calibrate this parameter is to first determine the parameters that define the fracture properties, and then adjust this parameter to obtain the desired compressive strength. For the purpose of this study, a value of 4.2 was selected.

\subsubsection{Frictional behavior}

Among the parameters describing the frictional behavior of the facets (i.e., shear boundary parameters), the initial friction coefficient, $\mu_{0}$, has the most effect in the compressive strength of the concrete. The effect of this parameter on the tensile and fracture response of concrete is minimal. However, in presence of compressive forces, this parameter contributes to increasing the shear strength of the facets. For normal-weight concrete, a suitable value for this parameter is 0.2 [21].

\subsection{Summary of calibration}

The reference calibrated LDPM model is selected based on the procedure described in the previous sections. Salient parameters are listed in Table 1 and Table 2. Fig. 7 shows representative experimental and simulated crack patterns for the calibrated model.

\section{SIMULATION OF LOAD TESTS ON GFRP RC BEAMS}

The calibrated concrete LDPM model was used to simulate the response of scaled GFRP $\mathrm{RC}$ beams that were previously load-tested in four-point bending [4], as presented in this section.

\subsection{Test setup and materials}

The experiments consisted of four-point bending tests on four GFRP RC beams without shear reinforcement [4]. The specimen geometry and test setup are summarized in Fig. 8 and Table 3.

Table 3: Specimen geometry for the tests

\begin{tabular}{l|c|c} 
& GS1, GS2 & GM1, GM2 \\
\hline$b_{w}[\mathrm{~mm}]$ & 229 & 114 \\
\hline$d[\mathrm{~mm}]$ & 146 & 292 \\
\hline$s[\mathrm{~mm}]$ & 457 & 914 \\
\hline$s / d$ & 3.1 & 3.1 \\
\hline$m[\mathrm{~mm}]$ & 305 & 305 \\
\hline$l_{d}[\mathrm{~mm}]$ & 610 & 610 \\
\hline
\end{tabular}

The specimens with effective depth of 146 $\mathrm{mm}$ and $292 \mathrm{~mm}$ are denoted as GS1 and GS2, and GM1 and GM2, respectively. The longitudinal elastic modulus and shear modulus of the GFRP bars were $49.3 \mathrm{GPa}$ and $7.39 \mathrm{GPa}$, respectively. Their mean ultimate tensile strength, $\sigma_{u}$, and shear strength, $\tau_{u}$, were 784.6 MPa and 204.1 MPa, respectively. The concrete used to fabricate the beams is 
described in Table 1 and Fig. 2, and is modeled as described in Section 3.2.

\subsection{LDPM simulations}

In the LDPM simulation, the GFRP RC beam is connected to the steel loading plate and the supports in the contact areas as depicted in Fig. 9.
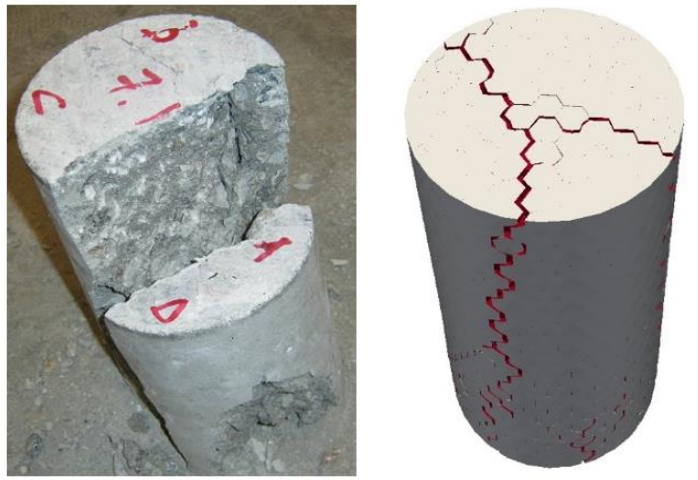

Figure 7: Typical fracture pattern for compression test in experiment and LDPM simulation

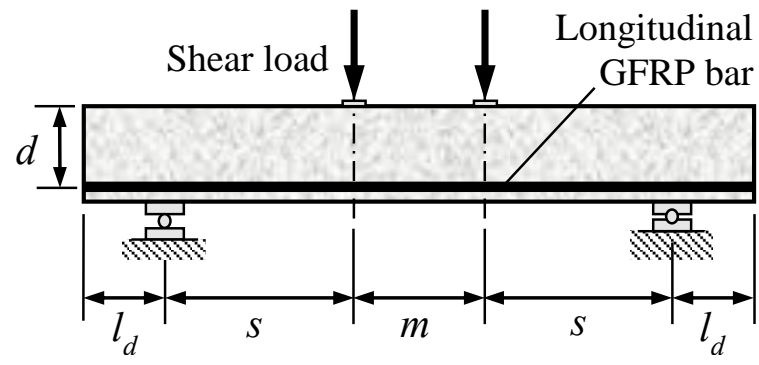

Figure 8: Schematic of test setup

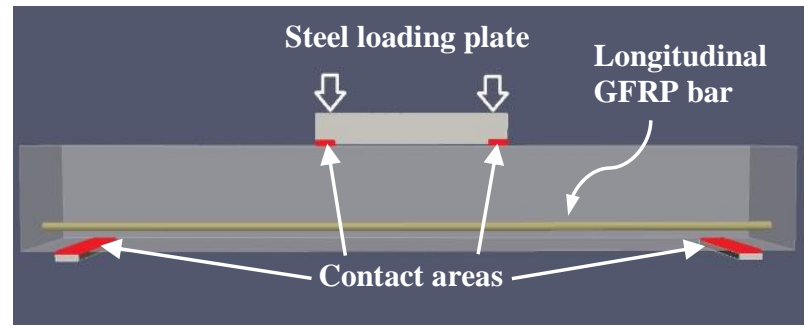

Figure 9: Schematics of simulated model

The interaction model between concrete and loading plate, and concrete and supports, is defined by a node-surface stiffness-based penalty contact algorithm [22]. The rebar nodes are connected to the adjacent concrete tetrahedrons using an elastic spring penalty algorithm to model perfect bond. The intent is to study whether modeling a perfect bond suffices to simulate shear behavior or a more realistic bond model needs to be implemented.

An explicit dynamic displacement-control loading procedure was used. The load was imparted at a constant velocity of $3 \mathrm{~cm} / \mathrm{s}$. The ratio of the kinetic energy to the internal work during the simulation was less than 0.01 indicating minimal inertial effects. The maximum time step of the simulation depends on the material properties and the length of the model components. A value of $0.0005 \mathrm{~ms}$ was selected for the maximum time step to ensure the convergence of the solution.

\section{RESULTS AND DISCUSSION}

Table 4 summarizes the experimental shear force at failure, $V_{e}$, the theoretical shear force associated with flexural failure, $V_{b}$, and the nominal shear strength, $V_{n}$, based on ACI 440 [3] and ACI $446[2,36]$ and the simulated shear strength of GS and GM specimens.

Table 4: Experimental and predicted shear strength

\begin{tabular}{|c|c|c|c|c|c|}
\hline \multirow[b]{2}{*}{ Specimen } & \multirow[b]{2}{*}{$\begin{array}{c}V_{e} \\
{[\mathrm{kN}]} \\
{[4]}\end{array}$} & \multirow[b]{2}{*}{$\begin{array}{c}V_{b} \\
{[\mathrm{kN}]} \\
{[4]}\end{array}$} & \multicolumn{2}{|c|}{$V_{n}[\mathrm{kN}]$} & \multirow[b]{2}{*}{$\begin{array}{c}V_{\text {simulated }} \\
{[\mathrm{kN}]}\end{array}$} \\
\hline & & & $\begin{array}{c}\mathrm{ACI} \\
440 \\
{[3]}\end{array}$ & $\begin{array}{c}\text { ACI } \\
446 \\
{[36]}\end{array}$ & \\
\hline GS1 & 44.2 & \multirow{2}{*}{43.8} & \multirow{2}{*}{11.5} & \multirow{2}{*}{20.7} & \multirow{2}{*}{49.3} \\
\hline GS2 & 46 & & & & \\
\hline GM1 & 22.7 & \multirow{2}{*}{43.7} & \multirow{2}{*}{11.4} & \multirow{2}{*}{17.3} & \multirow{2}{*}{36.7} \\
\hline GM2 & 17.8 & & & & \\
\hline
\end{tabular}

It is noted that specimens GS1 and GS2 did not fail in shear despite being designed to do so [4]. Instead, they failed near a loading section at a load in excess of the theoretical flexural strength associated with rupture of the GFRP bar (43.8 $\mathrm{kN}$ in Table 4), possibly due to significant aggregate interlocking contribution to shear strength. These results were not predicted through the ACI 440 [3] and ACI 446 [2,36] algorithms, further highlighting the importance of an effective modeling tool. Specimens GM1 and GM2 failed in shear at a load well below that associated with flexural failure. Both specimens suffered from size effect despite the relatively small effective depth $[2,4]$ and their strength was accurately predicted through the ACI 446 algorithm $[2,36]$. 
Fig. 10 and Fig. 11 present the experimental and numerical load-midspan displacement curves for the GS and GM specimens, respectively.

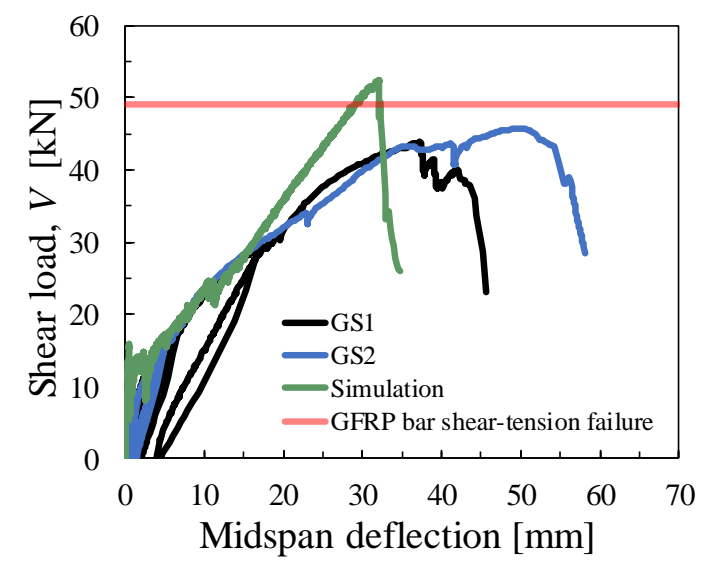

Figure 10: Experimental and simulated loaddisplacement response of GS specimens

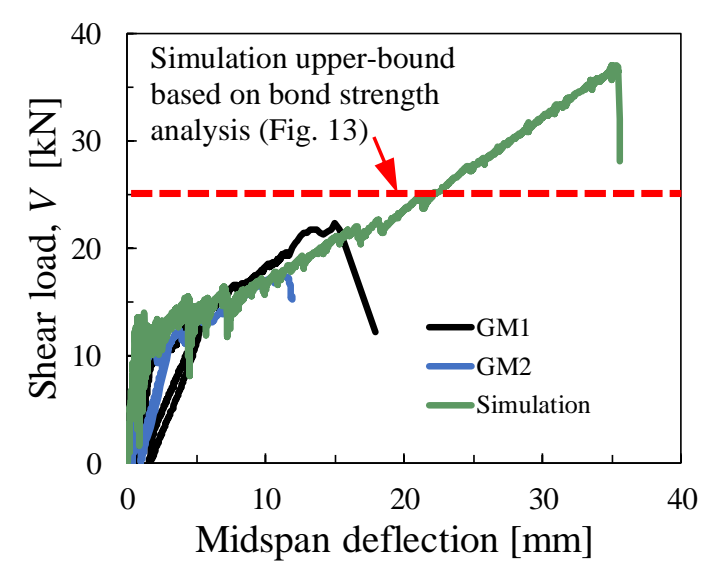

Figure 11: Experimental and simulated loaddisplacement response of GM specimens

For all specimens, the simulated results effectively approximate the elastic and postcracking flexural stiffness, and the cracking load. For the GS specimens, it appears that the strength is accurately predicted through the proposed model (Table 4 and Fig. 10), which undergoes a mixed shear-flexural failure, with rupture of the GFRP bar.

For the GM specimens, the proposed model largely overestimates the ultimate strength (Table 4 and Fig. 11). However, further analysis of the simulation results suggests that this overestimation stems from the assumption of perfect bond between the GFRP bar and the surrounding concrete. In fact, in the simulated model, critical shear cracks were fully formed at a shear force $V=16 \mathrm{kN}$, as shown in Fig.
12. At this stage, it is reasonable to expect an imminent failure. It is hypothesized that modeling a perfect GFRP bar-concrete bond led to an unrealistic behavior, which is highlighted by the formation of large diagonal cracks that are distributed along the GFRP bar along both shear spans. This is illustrated in Fig. 12 for $V=35 \mathrm{kN}$.

This hypothesis is corroborated by examining the GFRP bar-concrete bond (shear) stress along the length of the bar, as presented in Fig. 13. Here, the red bar indicates a realistic bond strength range [37]. It is noted that unrealistic bond stresses are generated in the model as critical shear cracks form at $V=16 \mathrm{kN}$. As the shear load reaches a value of $25 \mathrm{kN}$, unrealistically high bond stresses are produced along the shear spans (i.e., bar slip affects the entire shear spans). Therefore, $V=16 \mathrm{kN}$ and $25 \mathrm{kN}$ are herein considered as a reasonable lower and upper bound for the shear strength of the GM specimens, respectively. Further research is ongoing to test this hypothesis by introducing suitable bond stress-slip laws in the model.

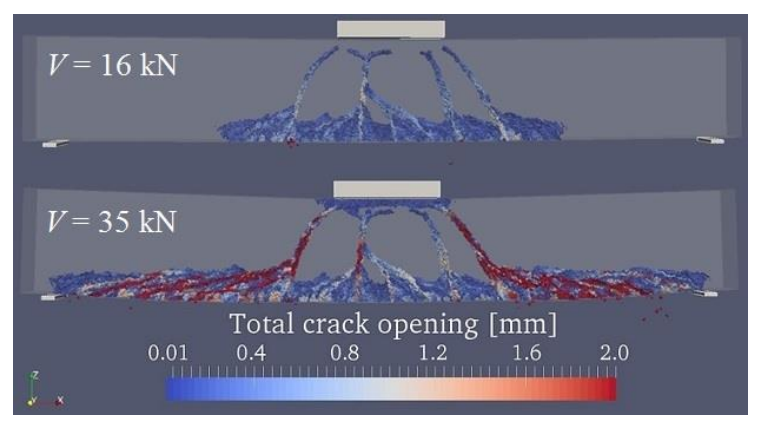

Figure 12: Simulation results of crack patterns in GM specimen for shear loads of $16 \mathrm{kN}$ and $35 \mathrm{kN}$

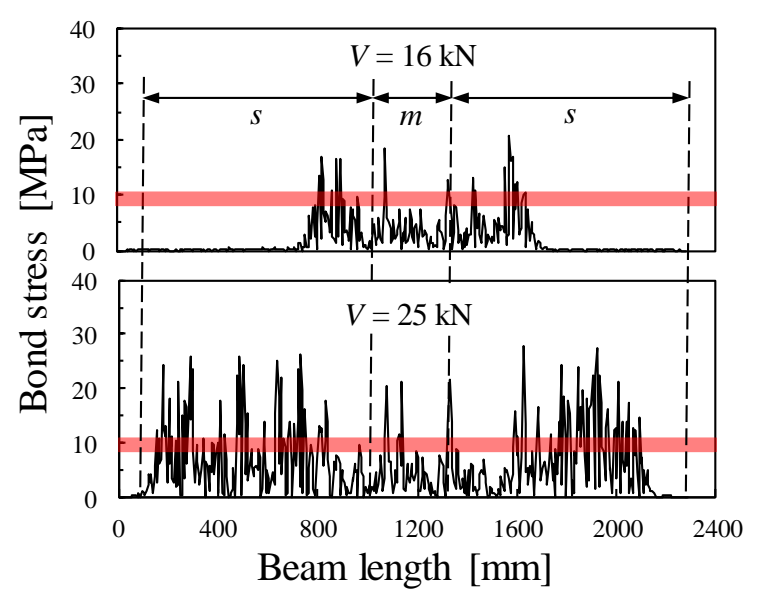

Figure 13: Bond stress along bar in GM specimens 
Fig. 14 shows the bond stress along the length of the GFRP bar in the GS specimens for $V=20 \mathrm{kN}$ and $40 \mathrm{kN}$.

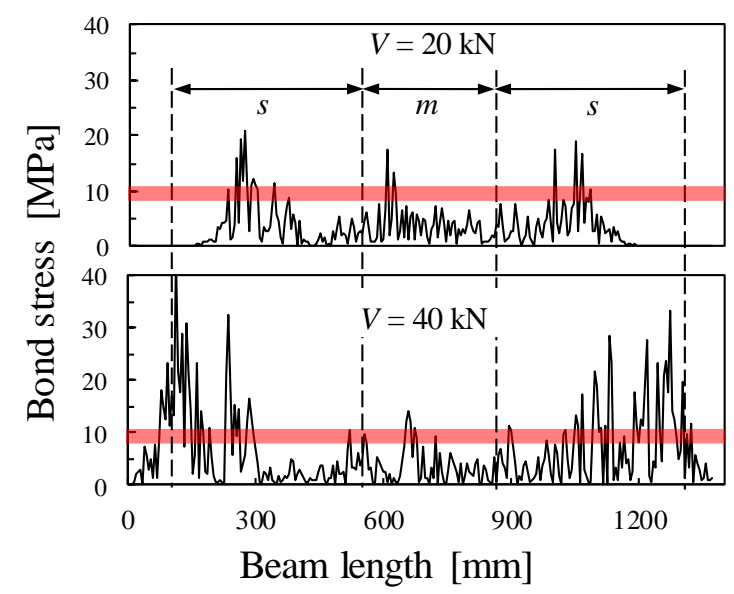

Figure 14: Bond stress along bar in GS specimens

Different from the simulation results for the GM specimens (Fig. 13), bond stresses exceeding the realistic strength range consistent with the literature [37] are attained at relatively high shear loads, and are not uniformly distributed along the shear spans. Instead, the bond stress peaks are attained in the vicinity of the supports, past which the beam specimens were built accounting for a conservative bar anchorage (development) length, $l_{d}=610 \mathrm{~mm}$ (Table 3 and Fig. 8). Under these conditions, it is reasonable to expect some local redistribution of the bond forces along the shear spans. Therefore, while the introduction of a suitable bond stress-slip law in the model may result in a more faithful simulation, the reduction in shear force at failure is not expected to be as significant as for the GM specimens.

\section{CONCLUSIONS}

Geometric and material model parameters of LDPM were calibrated based on the stressstrain response of concrete cylinders that were tested under uniaxial compression, and analysis of a literature database of meso-scale concrete parameters. The calibrated model was then used to simulate the behavior of scaled GFRP RC beams without stirrups, which were built using such concrete. These beams were designed to fail in shear, and were load tested in four-point bending. The results of the numerical simulations show that the proposed model accurately approximates the pre- and post-cracking load-midspan displacement response. However, the model fails to accurately predict the shear force at failure for the larger beams, which experienced diagonal shear failure. The analysis of the simulated bond stress along the length of the GFRP reinforcement suggests that the problem of inaccurate strength predictions may be resolved by implementing a suitable rebarconcrete bond stress-slip law in the LDPM model. Follow-on research to test this hypothesis is ongoing, including simulations on GFRP as well as steel RC slender beams for which detailed experimental results are available to the authors.

\section{ACKNOWLEDGEMENTS}

The authors gratefully acknowledge the support of the University of South Carolina (Department of Civil and Environmental Engineering) and Rensselaer Polytechnic Institute (Department of Civil and Environmental Engineering). Special thanks are extended to Engineering and Software System Solutions (ES3), Inc. for the precious technical assistance with the computational software MARS.

\section{REFERENCES}

[1] ASCE-ACI Committee 445 on Shear and Torsion. Recent Approaches to Shear Design of Structural Concrete. Journal of Structural Engineering 1998;124:1375417.

[2] Matta F, El-Sayed AK, Nanni A, Benmokrane B. Size Effect on Concrete Shear Strength in Beams Reinforced with Fiber-Reinforced Polymer Bars. ACI Structural Journal 2013;110:617-28.

[3] ACI Committee 440. Guide for the Design and Construction of Structural Concrete Reinforced with FRP Bars (ACI 440.1R15). 2015.

[4] Matta F, Mazzoleni P, Zappa E, Sutton MA, ElBatanouny M, Larosche AK, et al. Shear Strength of FRP Reinforced Concrete Beams Without Stirrups: 
Verification of Fracture Mechanics Formulation. ACI Special Publication 2012;286:1-14.

[5] Bentz EC, Massam L, Collins MP. Shear Strength of Large Concrete Members with FRP Reinforcement. Journal of Composites for Construction 2010;14:637-46.

[6] Vecchio FJ, Collins MP. The Modified Compression-Field Theory for Reinforced Concrete Elements Subjected to Shear. ACI Journal 1986;83:219-31.

[7] Hoult NA, Sherwood EG, Bentz EC, Collins MP. Does the Use of FRP Reinforcement Change the One-Way Shear Behaviour of Reinforced Concrete Slabs? Journal of Composites for Construction 2008;12:125-33.

[8] Sherwood EG, Lubell AS, Bentz EC, Collins MP. One-way shear strength of thick slabs and wide beams. ACI Structural Journal 2006;103:794-802.

[9] Bažant ZP, Jin-Keun Kim. Size Effect in Shear Failure of Longitudinally Reinforced Beams.pdf. ACI Journal 1984:456-68.

[10] Bažant ZP. Fracturing Truss Model: Size Effect in Shear Failure of Reinforced Concrete. Journal of Engineering Mechanics 1997;123:1276-88.

[11] Hillerborg A, Modéer M, Petersson P-E. Analysis of Crack Formation and Crack Growth in Concrete by Means of Fracture Mechanics and Finite Elements. Cement and Concrete Research 1976;6:773-81.

[12]Lee J, Fenves GL. Plastic-Damage Model for Cyclic Loading of Concrete Structures. Journal of Engineering Mechanics 1998;124:892-900.

[13]Dolbow J, Belytschko T. A Finite Element Method for Crack Growth Without Remeshing. International Journal for Numerical Methods in Engineering 1999;46:131-50.

[14] Bazant Z, Oh B. Crack band theory of concrete. Materials and Structures 1983;16:155.

[15] Caballero A, Carol I, López C. A MesoLevel Approach to the 3D Numerical Analysis of Cracking and Fracture of
Concrete Materials. Fatigue \& Fracture of Engineering Material Structures 2006;29:979-91.

[16] Bazant BZP, Tabbara MR, Member S, Kazemi MT, Pyaudier-cabot G. Random particle model for fracture of aggregate or fiber composites. Journal of Engineering Mechanics 1991;116:1686-705.

[17]Leite JPB, Slowik V, Mihashi H. Computer Simulation of Fracture Processes of Concrete Using Mesolevel Models of Lattice Structures. Cement and Concrete Research 2004;34:1025-33.

[18] Yip M, Li Z, Liao B, Bolander J. Irregular Lattice Models of Fracture of Multiphase Particulate Materials. International Journal of Fracture 2006;140:113-24.

[19] Cusatis G, Bažant ZP, Cedolin L. Confinement-Shear Lattice CSL Model for Fracture Propagation in Concrete. Computer Methods in Applied Mechanics and Engineering 2006;195:7154-71.

[20] Cusatis G, Pelessone D, Mencarelli A. Lattice Discrete Particle Model (LDPM) for Failure Behavior of Concrete. I: Theory. Cement and Concrete Composites 2011;33:881-90.

[21] Cusatis G, Mencarelli A, Pelessone D, Baylot J. Lattice Discrete Particle Model (LDPM) for Failure Behavior of Concrete. II: Calibration and Validation. Cement and Concrete Composites 2011;33:891905.

[22] Pelessone D. MARS, Modeling and Analysis of the Response of Structures. User's Manual, ES3 Inc. 2016.

[23] Alnaggar M. Multiscale Modeling of Aging and Deterioration of Reinforced Concrete Structures. PhD Dissertation, Northwestern University, 2014.

[24] Alnaggar M, Cusatis G. Automatic Parameter Identification of Discrete Mesoscale Models with Application to the Coarse-Grained Simulation of Reinforced Concrete Structures. 20th Analysis and Computation Specialty Conference 2012:406-17.

[25] Domonell EM. Lattice Discrete Particle Modeling of Reinforced Concrete. MS Thesis, Rensselaer Polytechnic Institute, 
2011.

[26] Kaw AK. Mechanics of Composite Materials. CRC Press, Boca Raton, FL; 2005.

[27]Reissner E. The Effect of Transverse Shear Deformation on the Bending of Elastic Plates. Journal of Applied Mechanics 1945:69-77.

[28] MacGregor JG, Wight JK. Reinforced Concrete Mechanics and Design, Sixth Edition. 2011.

[29] Cusatis G, Cedolin L. Two-Scale Study of Concrete Fracturing Behavior. Engineering Fracture Mechanics 2007;74:3-17.

[30]ACI Committee 318. Building Code Requirements for Structural Concrete (ACI 318-14) and Commentary. 2014.

[31]Bažant ZP, Becq-Giraudon E. Statistical Pprediction of Fracture Parameters of Concrete and Implications for Choice of Testing Standard. Cement and Concrete Research 2002;32:529-56.

[32] Kwon SH, Zhao Z, Shah SP. Effect of specimen size on fracture energy and softening curve of concrete: Part II. Inverse analysis and softening curve. Cement and Concrete Research 2008;38:1061-9.

[33]Rosselló C, Elices M, Guinea GV. Fracture of model concrete: 2. Fracture energy and characteristic length. Cement and Concrete Research 2006;36:1345-53.

[34] Wendner R, Vorel J, Smith J, Hoover CG, Bažant ZP, Cusatis G. Characterization of Concrete Failure Behavior: a Comprehensive Experimental Database for the Calibration and Validation of Concrete Models. Materials and Structures 2015;48:3603-26.

[35] RILEM Recommendation. Determination of the fracture energy of mortar and concrete by means of three-point bend tests on notched beams. Materials and Structures 1985;18:285-90.

[36] Bažant ZP, Yu Q, Gerstle W, Hanson J, Ju JW. Justification of ACI 446 Code Provisions for Shear Design of Reinforced Concrete Beams. ACI Structural Journal 2007;104:601-10.
[37] Benmokrane B, Tighiouart B, Chaallal O. Bond Strength and Load Distribution of Composite GFRP Reinforcing Bars in Concrete. ACI Materials Journal 1996;93:246-53. 